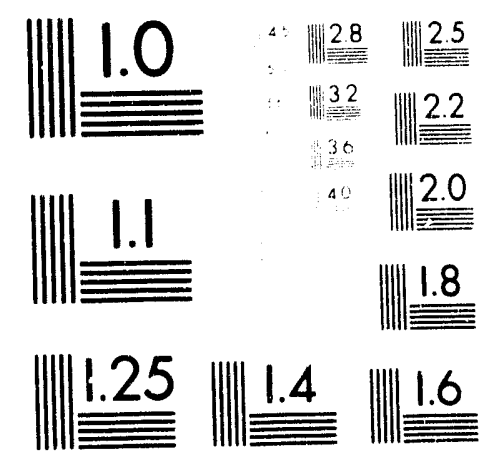



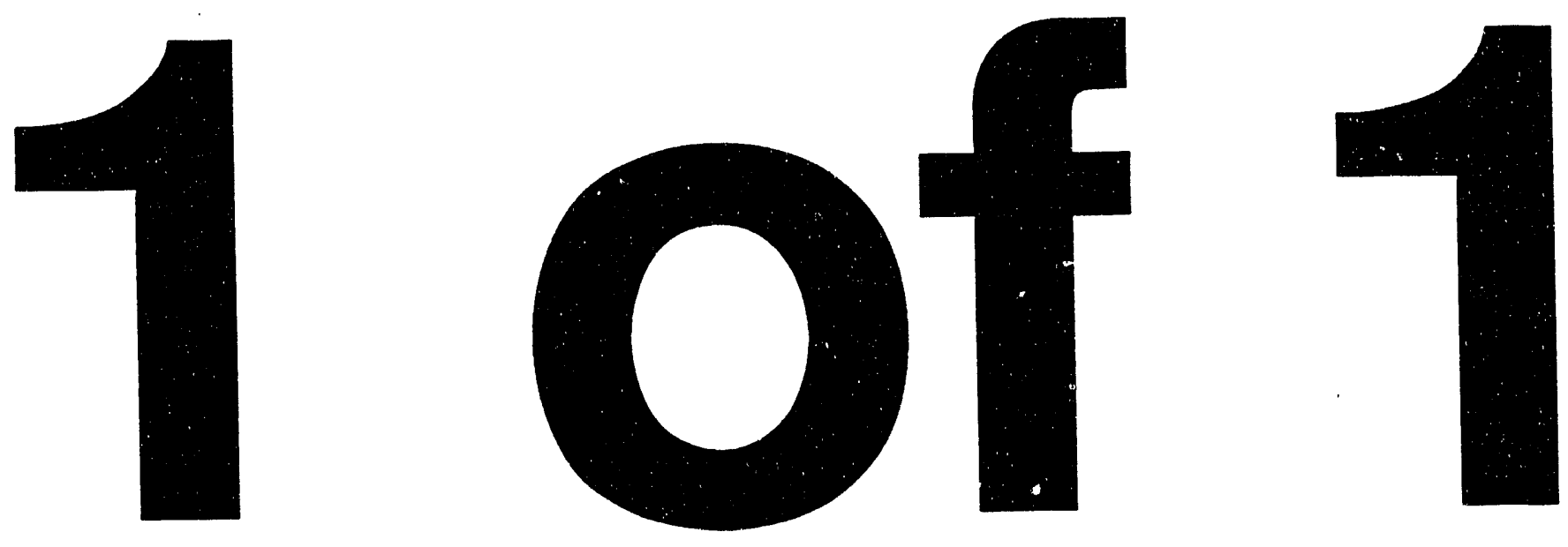


\title{
INVESTIGATION OF HIGH STRAINS AT THE BOTTOM OF THE LOS ALAMOS CONFINEMENT VESSEL
}

\begin{abstract}
DISCLAIMER
This report was prepared as an account of work sponsored by an agency of the Unted States Government Neither the linited States (jovernment nor any agency thereof, nor any of their employees, makes any warranty, expre's or implied. or assumes any legal hability or responsibility for the accuracy. completeness, or usefulness of any information, apparatus, product, or process disclosed, or represents that its use wrould not infringe privately owned rights. Reference herein to any specific commercial product, process, or service hy trade name, trademark, manufacturer, or otherwise does not necessarily constitute or imply its endorsement, recommendation, or favoring hy the I/nited states (iovernment or any agency thereof. The views and opinions of authors expressed herein do not necessarily state or reflect those of the United States (iovernment or any agency thereof
\end{abstract}

\section{September 30, 1992}

\author{
Barbara B. Lewis \\ APTEK, Inc. \\ 1257 Lake Plaza Drive \\ Colorado Springs, CO 80906
}




\title{
Investigation of High Strains at the Bottom of the Los Alamos Confinement Vessel
}

\author{
Barbara B. Lewis \\ APTEK, Inc. \\ 1257 Lake Plaza Dr. \\ Colorado Springs, CO 80906
}

September 30, 1992

\section{Summary}

In helping Los Alamos to understand the vessel response of explosive confinement vessels, AP'TEK has provided analysis of a 6 foot diameter vesse! subjected to a spherical explosive blast [3]. Correlations between analysis and test were very good except at the bottom of the vessel. A beating response was seen in the tests which reinforced the primary response mode at the bottom of the vessel, possibly to the extent of causing local yielding at the bottom. We did not predict the beating response and could not explain its origin. Since both APTEK and LANL felt that understanding these strains was important, we investigated the nature and possible origins of the response.

We originally suspected that the high strains at the bottom were caused by some asymmetry which could not be represented in the quarter symmetric model previously used. In order to capture this response, we modelled the full vessel and included the thickness variation over the entire vessel as well as possible. From analysis of this model, we identified a mode shape which we believe corresponds to the beating response measured in the tests. However, the analysis did not show a significant contribution of this mode to the overall response, and therefore did not not predict the high strains at the bottom of the vessel. We then began a systematic study of the effects of various parameters of the problem. In separate analyses, we added boundary conditions, increased the mass of the ports by 10 percent, and included a row of 10 
percent stiffer material to represent the weld. Of these, only the added boundary condition had a significant effect, and the boundary condition applied (vertical fixity at the bottom of two opposite ports to simulate the slings used) caused the strains at the bottom to decrease.

We also made a less refined quarter-symmetric model with three elements through the thickness to perform a modal analysis. We found mode shapes similar in character to the deformed shapes obtained from the dynamic response. We theorized that the pressure reflections in the vessel were exciting one of these modes in the test but not in the analysis. We changed the timing of the pressure reflections to coincide with the suspected secondary response mode. For a 15 percent change in the timing of the pressure pulses, and with no change in the magnitude of the pressure, we obtained an increase in vessel strains at the bottom of over 40 percent.

'This report describes the work done by APTEK to determine the cause of the high strains at the bottom of the sphere. Details of the analyses are presented in the next section. Conclusions and recommendations are given in Section 3 . 


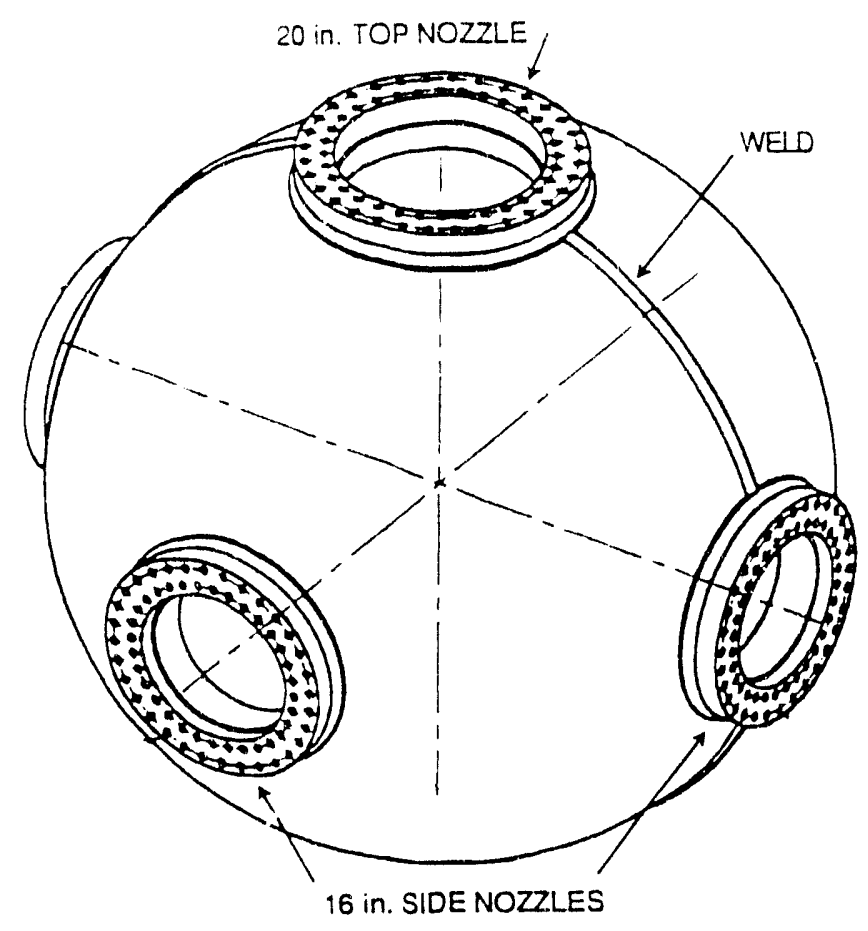

Figure 1: Benchmark confinement vessel.

\section{Analyses}

\subsection{Development of Full Vessel Model}

The benchmark confinement vessel tested at Los Alamos is shown in Figure 1. The structure is a steel sphere, 36 inches internal radius, which was made by welding two hemispheres together. The thickness of the sphere varies from about 2.70 inches at the weld to 2.16 inches at the pole. The sphere has a 20 inch diameter port on the top and four 16 inch ports spaced equally around the equator of the sphere. The top port and two opposite side ports are centered on the weld. Each port consists of a nozzle, which is a thick stiffening ring welded to the sphere, and a door bolted to the nozzle. We had previously modelled only a fourth of the structure as shown in Figure 2. The rationale for using quarter symmetry was that the load is at the center and is axisymmetric, placement and symmetry of the ports can be represented using quarter symmetry, and variations in the shell thickness could be well represented by a smooth variation from pole to weld - also quarter symmetric.

The quarter symmetric finite element model consisted of over 16,000 hexagonal elements with five through the thickness to adequately represent bending. The reason 


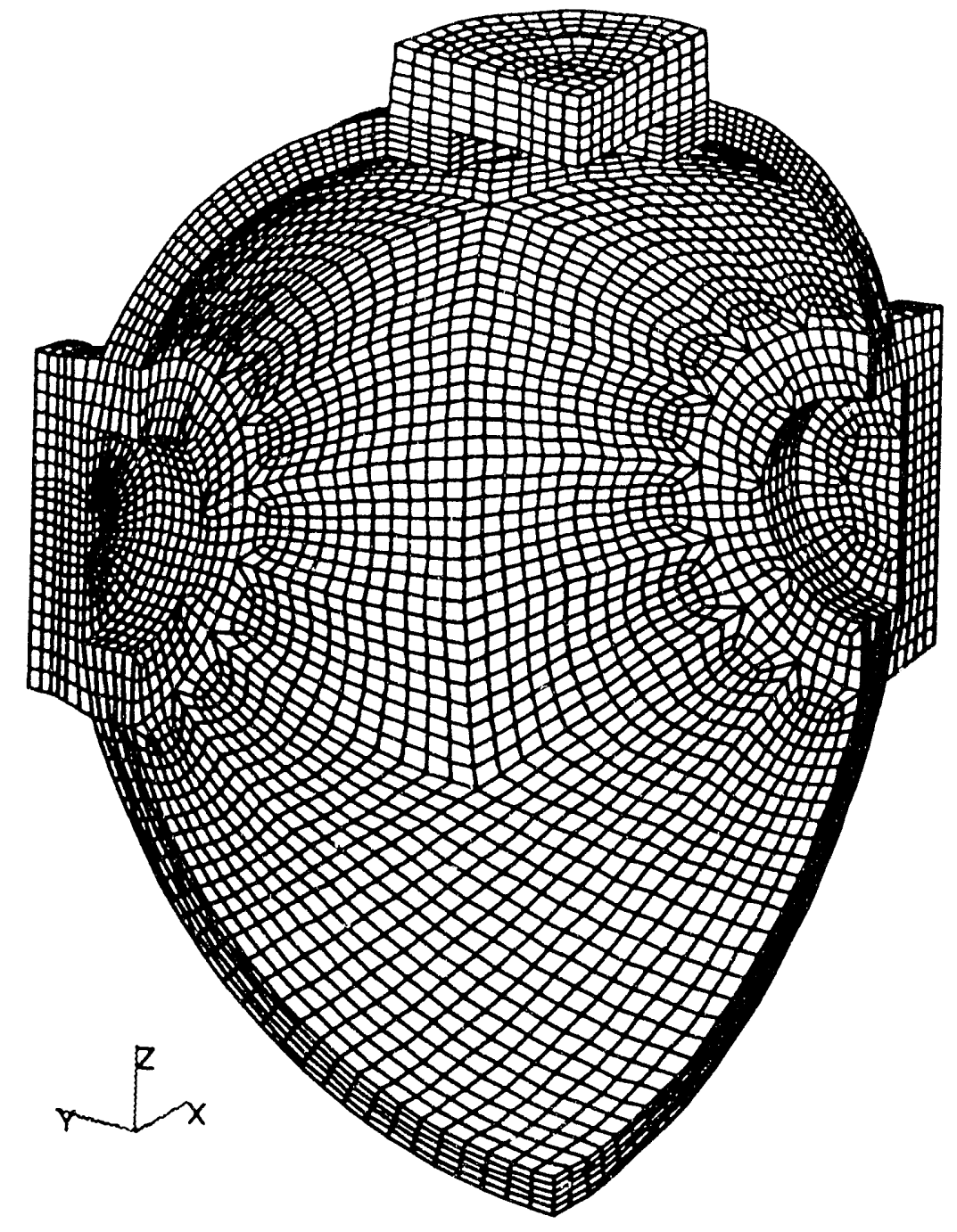

Figure 2: Quarter-symmetric finite element model of benchmark confinement vessel using hexagonal elements. 
that the original inodel had so many elements was that the aspect ratio of a finite clement must be controlled to obtain good results. The aspect ratio of an element is the ratw of its lingest dimension to its shortest dimension. Aspect ratios should ileally bi nne, and a good rule of thumb is not to exceed four or five. It was necessary to use a large number of elements to have five elements through the thickness of the sphere and keep the aspect ratios of the elements reasonable. The size of the model made manipulation cumbersome in terms of computer resources (both hardware and software) and analsi time and understanding. It $w$, uld have been very difficult if not impossible to use a model four times the size of the quarter-symmetric model to represent the full vessel. Therefore we decided to investigate the use of thick shell elements for defining the full model.

Thick shell elements are a relatively new addition to DYNA3D [2] and, although they have been used with good results, are still considered experimental. We checked out the thick shells against the previous analysis to validate their use. We used PA'RAN [5] to model a quarter of the structure using 1460 thick shell elements to represent the shell of the vessel and 1236 hexagonal elements to represent the nozzles and port doors. We defined five integration points through the thickness of each thick shell element, which is equivalent to using five hexagonal elements through the thickness. Since a single thick shell replaces five hexagonal elements through the thickness, a good aspect ratio can be maintained while still using less elements circumferentially on the shell than before. While this gives more than a five-fold decrease in the number of elements needed, each thick shell element takes longer to process, so the total analysis time was not decreased as significantly as the number of elements.

The thick-shell quarter-symmetric model is shown in Figure 3. It was analyzed for a pressure load corresponding to a 40-lb explosive charge. The load used is shown in Figure 4. Figure 5 shows comparisons of the analysis results using thick shells and hexagonal elements along with measured strain data. Variations between the analysis results were not significant so we felt justified in using the thick shell elements to model the full vessel. 


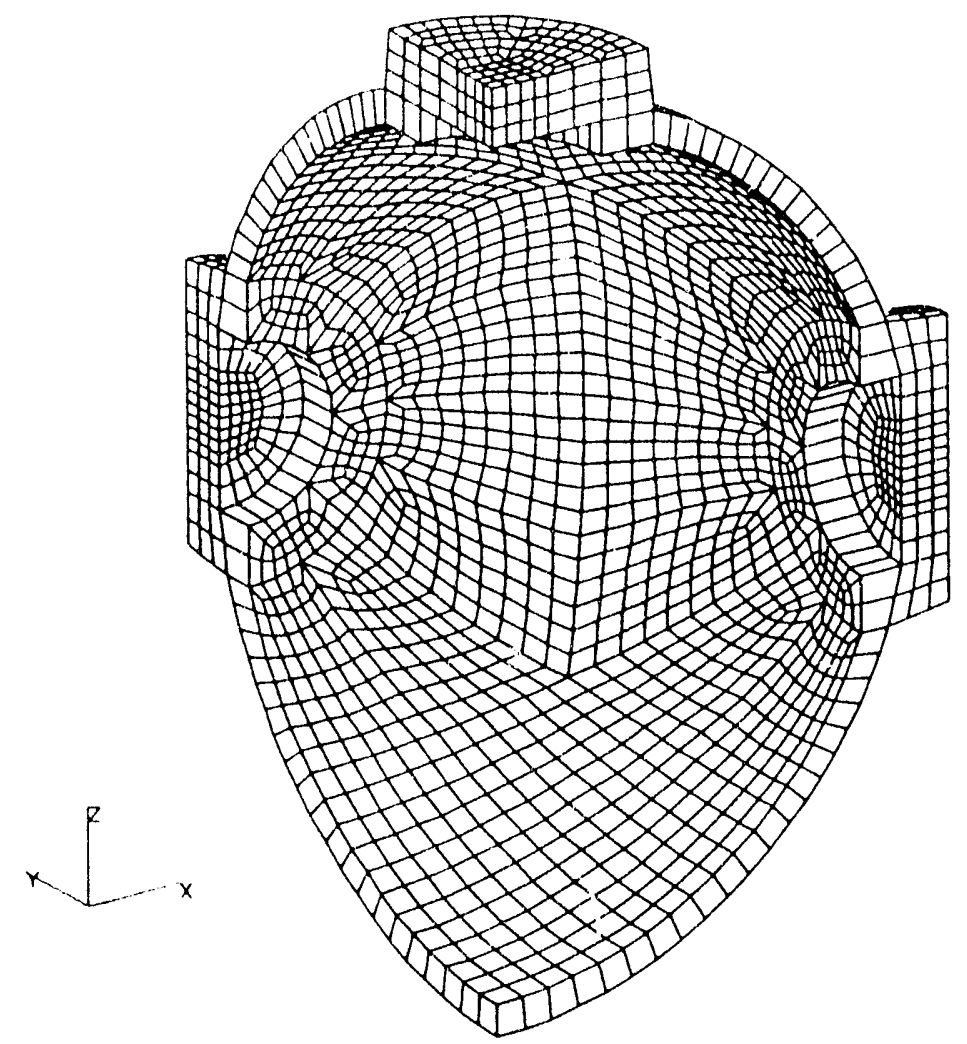

Figure 3: Quarter-symmetric finite element model of benchmark confinement vessel using thick-shell elements.

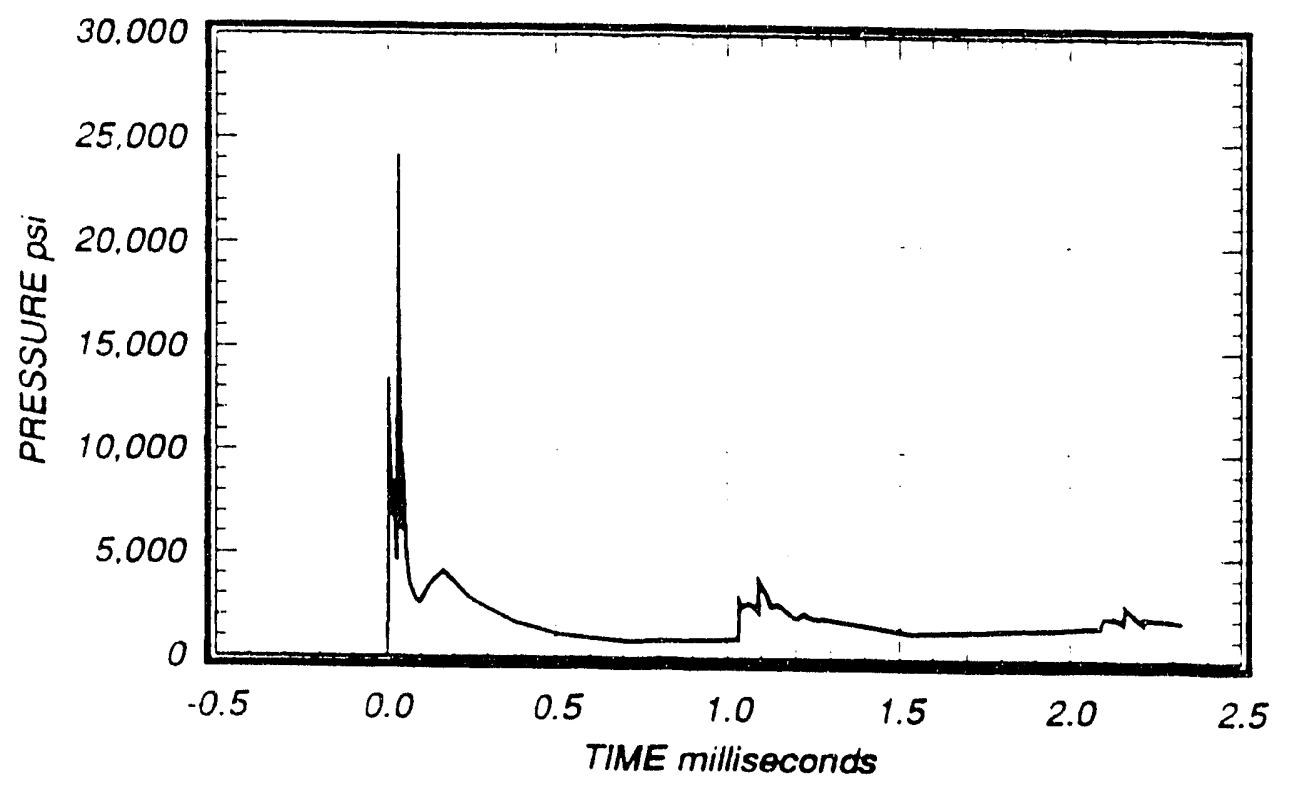

Figure 4: Pressure load for $40 \mathrm{lb}$ charge analysis. 

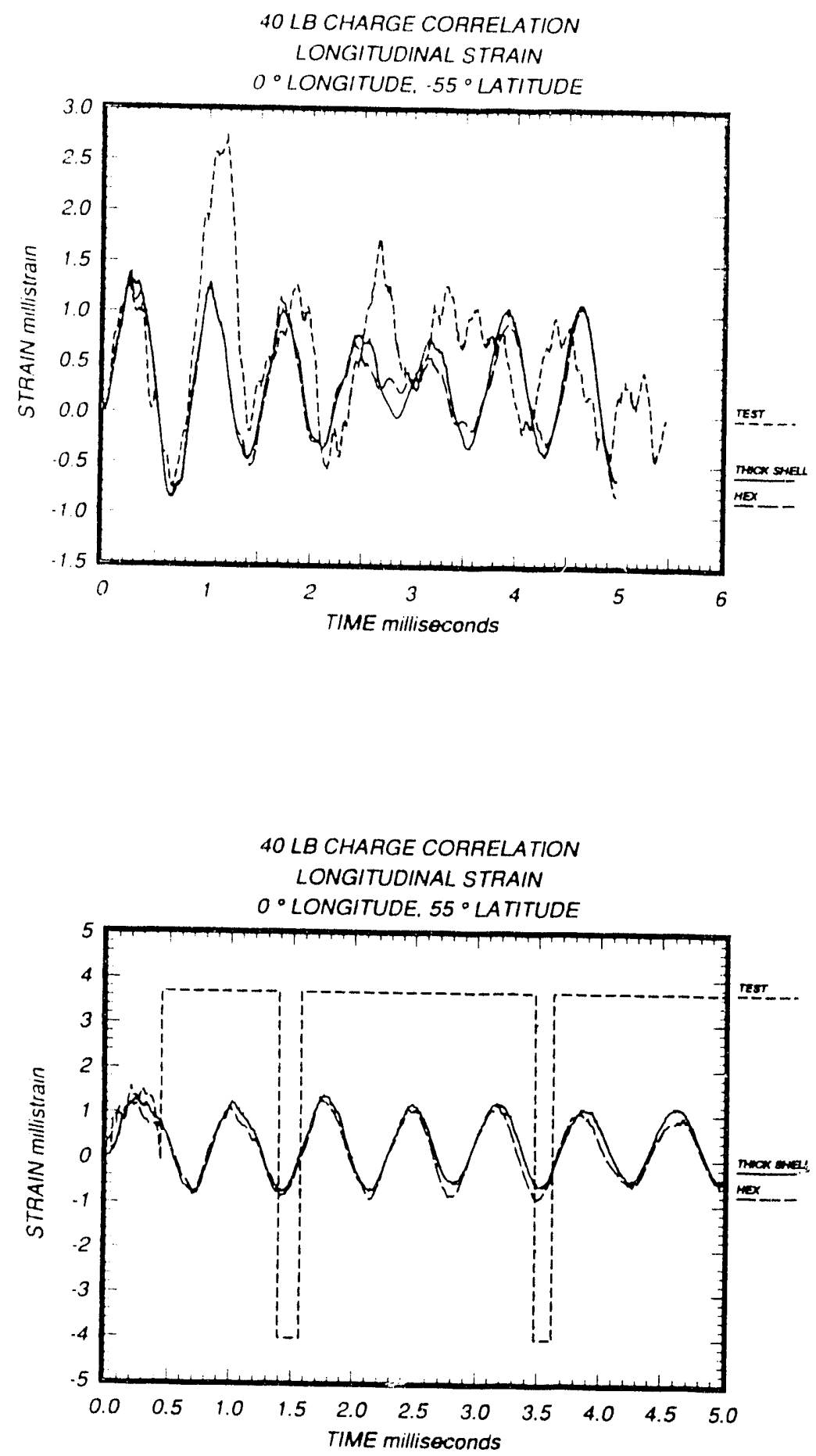

Figure 5: Comparison of thick-shell element and hexagonal element results. 
Table 1: Material properties used for confinement vessel analysis.

\begin{tabular}{||c|c||}
\hline \multicolumn{2}{|c|}{ A537 Class 2 Steel } \\
\hline Density & $0.28 \mathrm{lb} / \mathrm{in}^{3}$ \\
Elastic Modulus & $30.0 \times 10^{6} \mathrm{psi}$ \\
Poisson's Ratio & 0.30 \\
Yield Stress & $80,000 \mathrm{psi}$ \\
Tangent Modulus & $1.0 \times 10^{5} \mathrm{psi}$ \\
\hline
\end{tabular}

\section{$2.2 \quad$ Full Vessel Model}

The most readily identifiable non-symmetry of the vessel is the shell thickness. LANL measured the thickness of the vessel wall along the vertical and horizontal circles prior to modifying the vessel to the benchmark configuration. The vessel originally had one $16 \mathrm{inch}$ side port and an $8 \mathrm{inch}$ side port located at the opposite poles of the welded hemispheres. The $20 \mathrm{inch}$ top port also existed prior to modification. Figure 6 shows the thickness measurements starting at the 16 inch port and moving angularly around the vessel through the weld and over to the $8 \mathrm{inch}$ port. The gap in the data around the tup of the vessel is due to the presence of the 20 inch top port. There is a difference between the thicknesses of the two hemispheres. Also, although the data points are fairly coarse, it appears that the weld may be slightly off-center. That is, the peak thicknesses (indicating the weld) were measured at angles between 90 and 100 degrees, not all at 90 degrees as would be expected. Figure 7 shows the model we created for the full vessel analysis. We interpolated the thickness of the shell at each nodal location from the measured data and moved the outer nodes to give the correct thickness. Figure 8 shows graphically the variation in average element thickness of the shell elements. The element thicknesses range from about 2.2 inches represented by dark blue to 2.7 inches represented by orange. We used the A537 Class 2 steel material properties given in Table 1. The 40-1b pressure load was applied to all inside surfaces as before and the response was analyzed using DYNA3D.

The response at the bottom of the vessel predicted using the full model was not very different than that predicted using the quarter-symmetric model. We saw no increase in strains at the bottom using the full model. We used TAURUS [1] to examine the results. We looked at deformed shapes with a large multiplication factor on the displacements to better understand the response. Figure 9 shows one of the deformed shapes which we believe to be the secondary response mode causing the problem. We obtained this shape by magnifying the computed displacements by a factor of 1000 at a time when the membrane response passes through zero. The characteristics of 


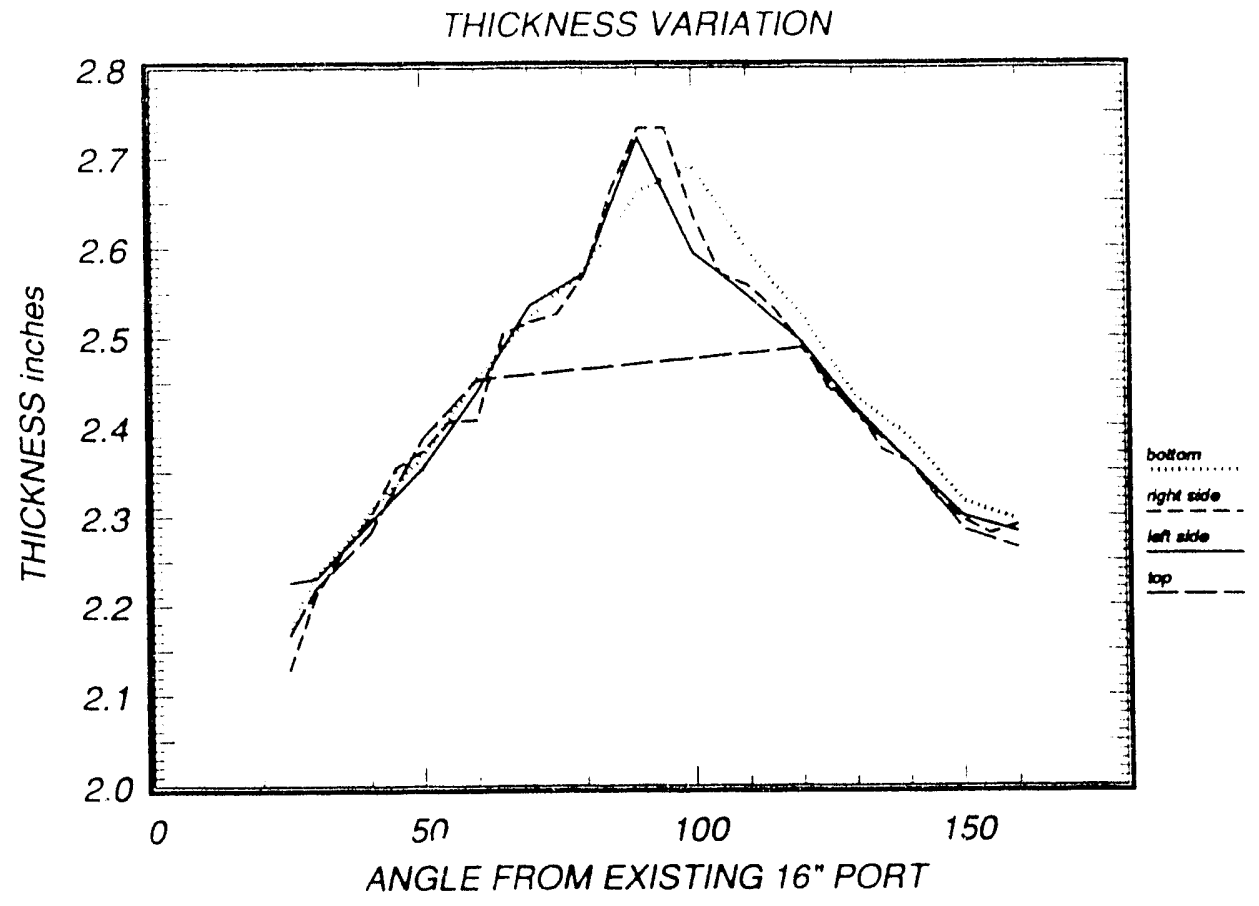

Figure 6: Measured thickness variation in benchmark confinement vessel.

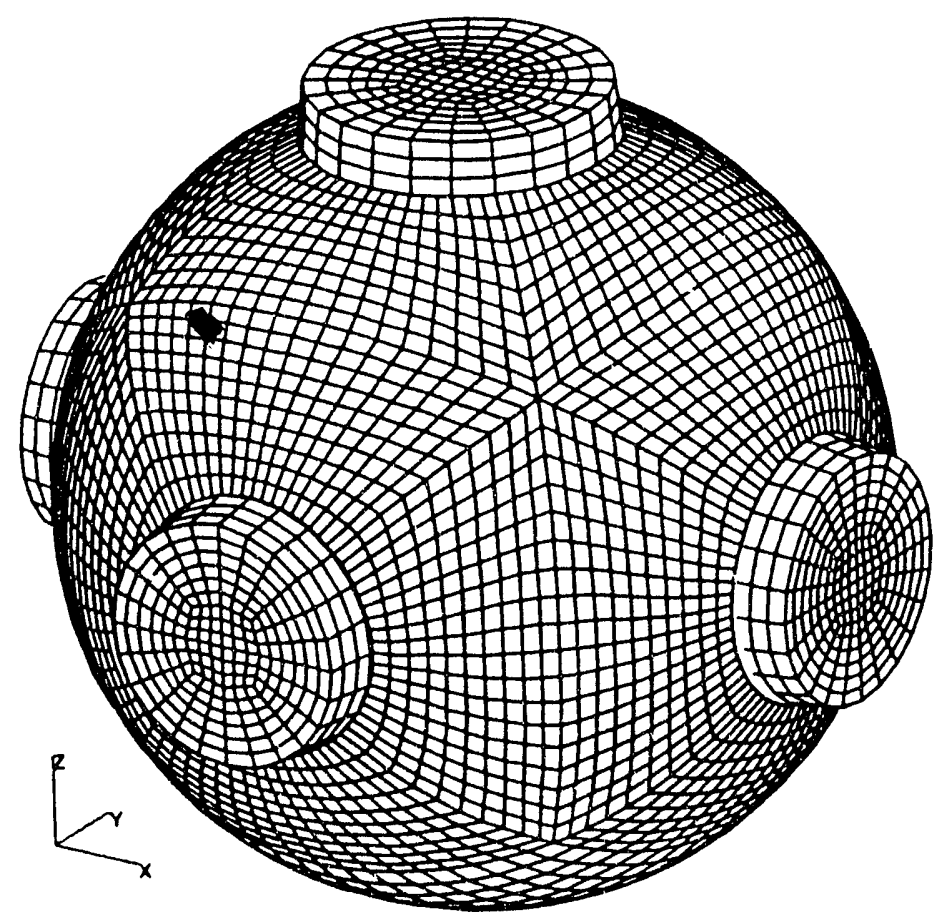

Figure 7: Finite element model of full vessel. 

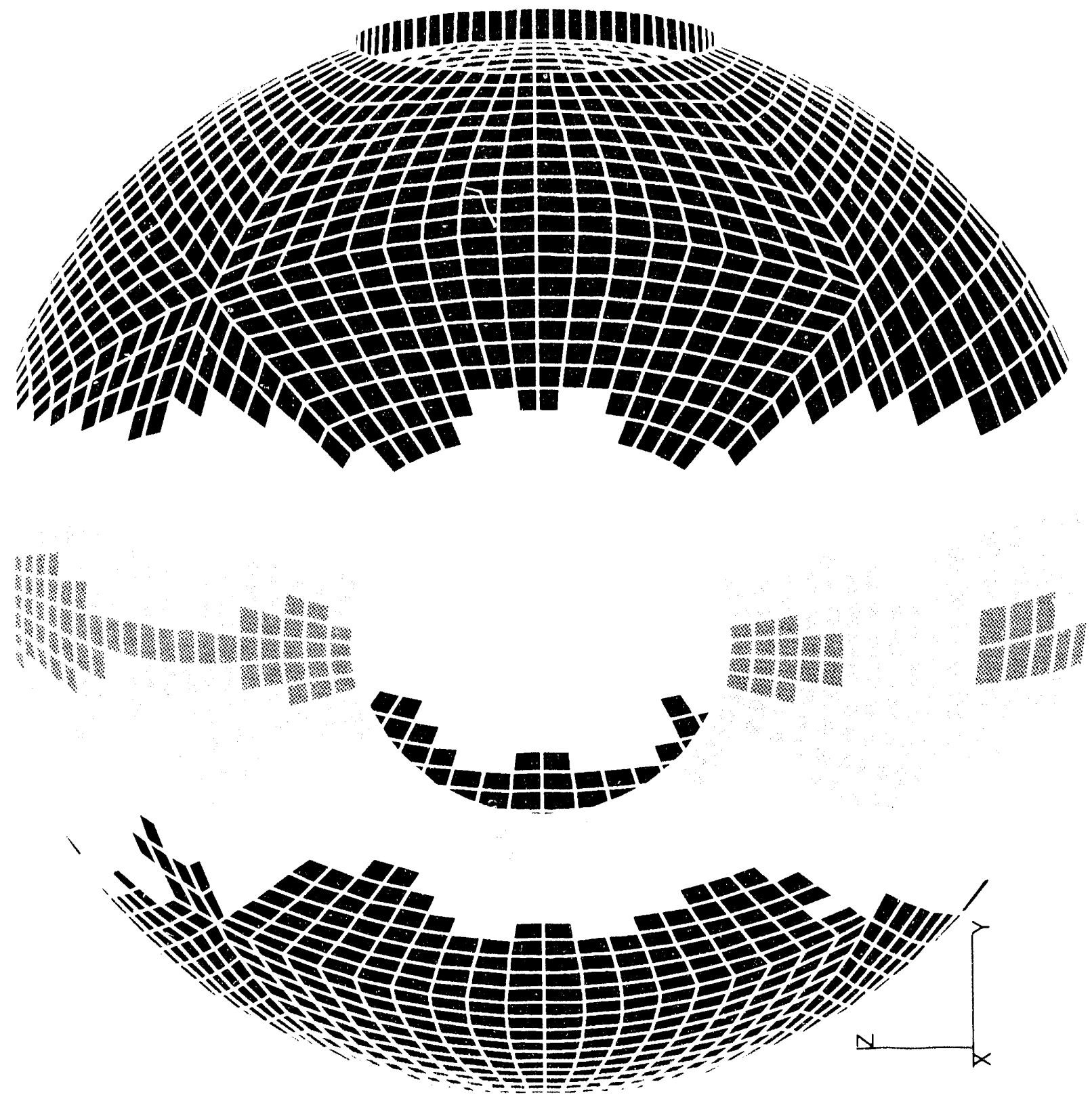

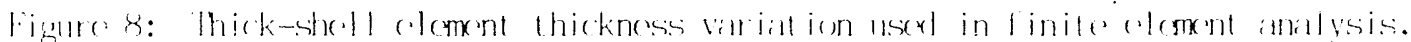




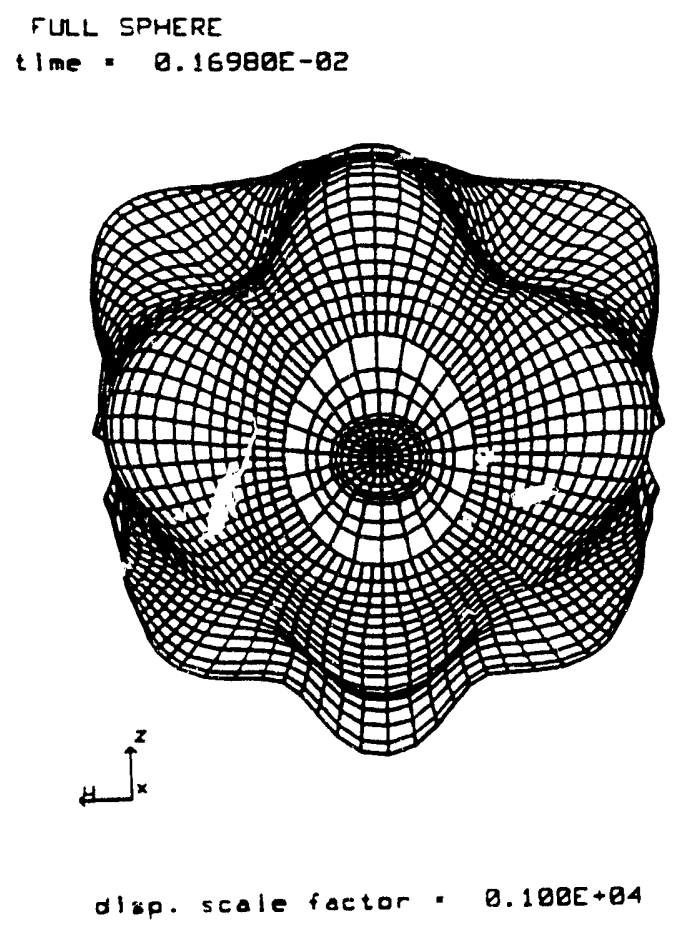

Figure 9: Deformed shape showing secondary response.

this shape fit well with the measured response; the strains at -55 degrees latitude and () and 45 degrees longitude are out of phase and there is a symmetric bulge at the bottom of the vessel. We concluded that the correct response is contained in the finite element model, but is not being driven as it is in the test. In fact, closer inspection of this shape shows that it is quarter-symmetric and should have also been contained in the quaitier-symmetric model.

We then began to look for effects other than the thickness variation that could possibly drive the bending mode predicted. The first effect studied was the boundary condition. The tested rossel was hung by woven slings which went around the two off-weld ports. We applied a vertical constraint to those ports at the center bottom nodes only. The effect of the boundary condition was to decrease the strains at the bottom at later times.

The next effect studied was the presence of the weld material. LANL had the thickness of the vessel measured at ten locations across the weld at approximately every ten degrees around the weld circumference. There was a variation from one side of the weld to the other and the weld had a thickness variation. The greatest thickness variation (highest to lowest measured points) was on the order of $0.1 \mathrm{inch}$. This is less than a four percent difference in thickness and we did not think it warranted the effort required to accurately model the weld. However, we did investigate the effect 
of stiffer material at the weld line. We changed the material properties of a row of elements to one side of the centerline where the two hemispheres joined. This row of elements was given properties ten percent higher in all respects than the rest of the sphere. We looked at two parameters in this analysis: the inclusion of a stiffer material to represent the weld, and the asymmetry of an off-centered weld which we suspect is the true case. The results showed almost no difference due to the weid.

The last analysis done with the full splare model was with increased mass in the ports. The density of the port material was increased by ten percent to see the effect of a mass change of the ports. Again, the results were very similar to the original full sphere model results. 


\subsection{Modal Analysis and Load Modification}

It became clear that we needed a better understanding of the modes present in the structure. The NIKE3I) [4] finite element code can be used to determine normal modes of a structure, but it has some limitations. NIKE3D forms stiffness and mass matrices from which it determines eigenvalues and eigenvectors which are the natural frequencies and mode shapes of the structure. The matrices become very large for sizable problems, requiring large amounts of computer memory to solve the eigenproblem. NIKE3D does not presently have a thick shell element, and can not determine modes when tied or sliding interfaces are present. So we made yet another quartersymmetric finite element model for eigenvalue determination. It has three elements through the thickness, the minimum required for representation of bending, and does include the average thickness variation. Since rigid body (zero frequency) modes must be constrained, one node at the bottom center of the off-weld port was constrained in the vertical direction. This is equivalent to the boundary condition used in the full sphere with sling analysis. The horizontal translations and all rigid body rotations were automatically constrained by the boundary conditions applied for quarter symmetry.

We obtained the first 26 modes and mode shapes for the structure. Some of the shapes are shown in Figures 10 and 11. The time listed on the plot is the natural frequency in radians per second. Two shapes are particularly of interest. The primary response mode is that shown in Figure 12. We have called it the primary membrane or "breathing" mode, but there is a lot of bending of the port nozzles showing that the ports are influential in this mode. The frequency is 8776 radians/second or 1397 $\mathrm{IIz}$ which matches the predicted primary response in the dynamic response analysis. The shape is also quite similar to the shape predicted at the first peak response for the thick-shell quarter-symmetric dynamic response analysis shown in Figure 13. 

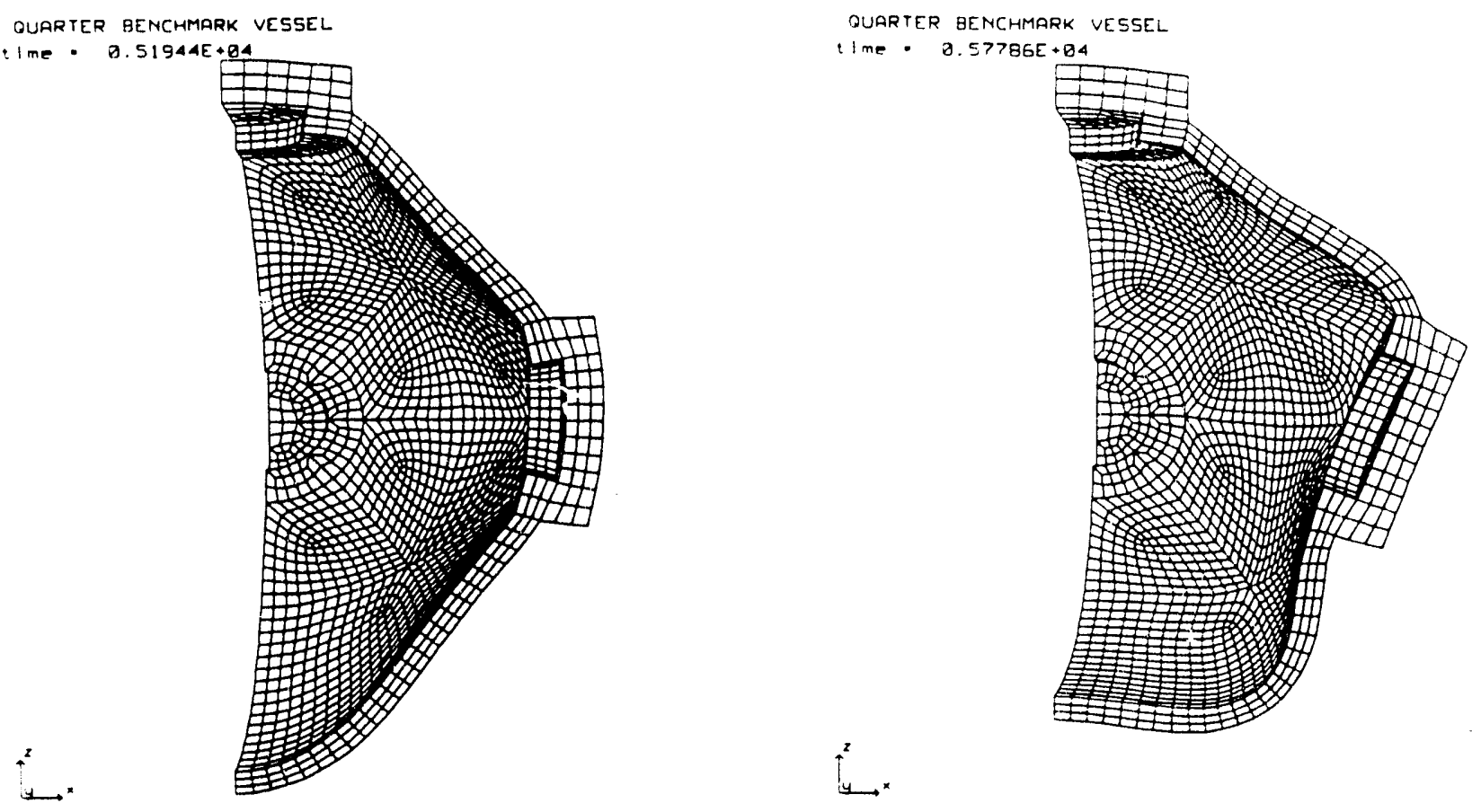

OUARTER BENCHMARK VESSEL

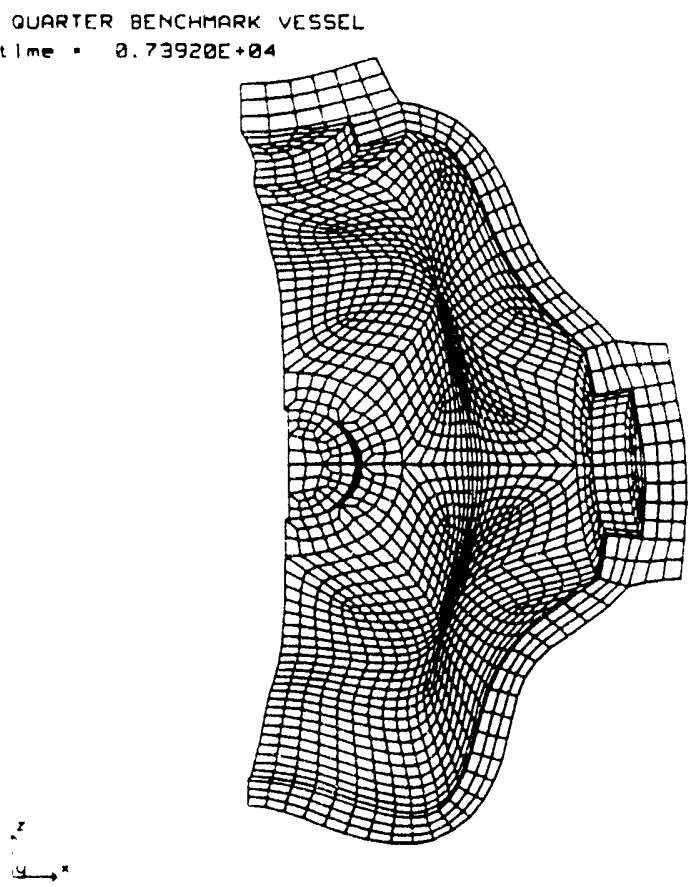

Figure 10: Predicted mode shapes of quarter-symmetric vessel. 

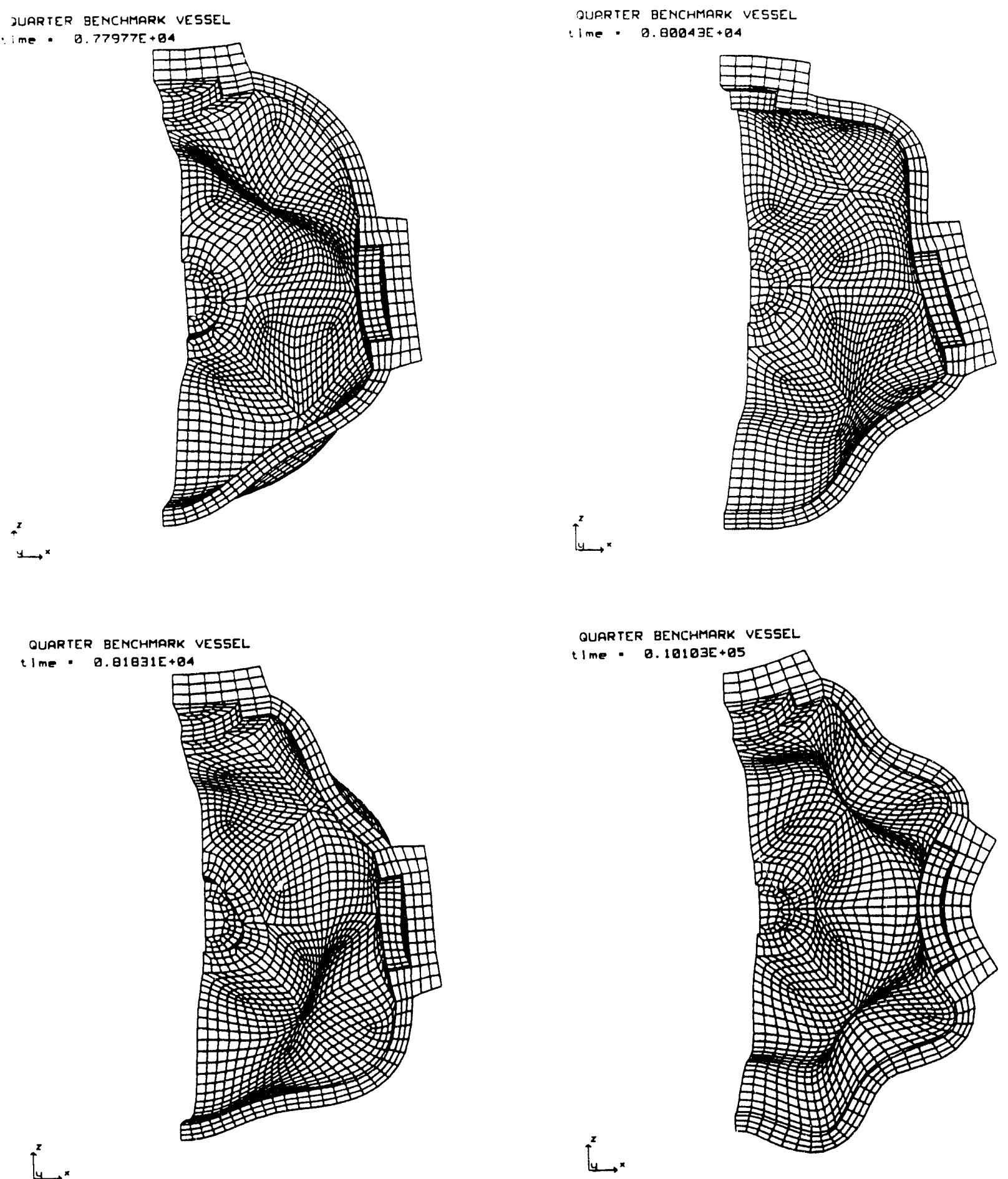

Figure 11: Predicted mode shapes of quarter-symmetric vessel. 


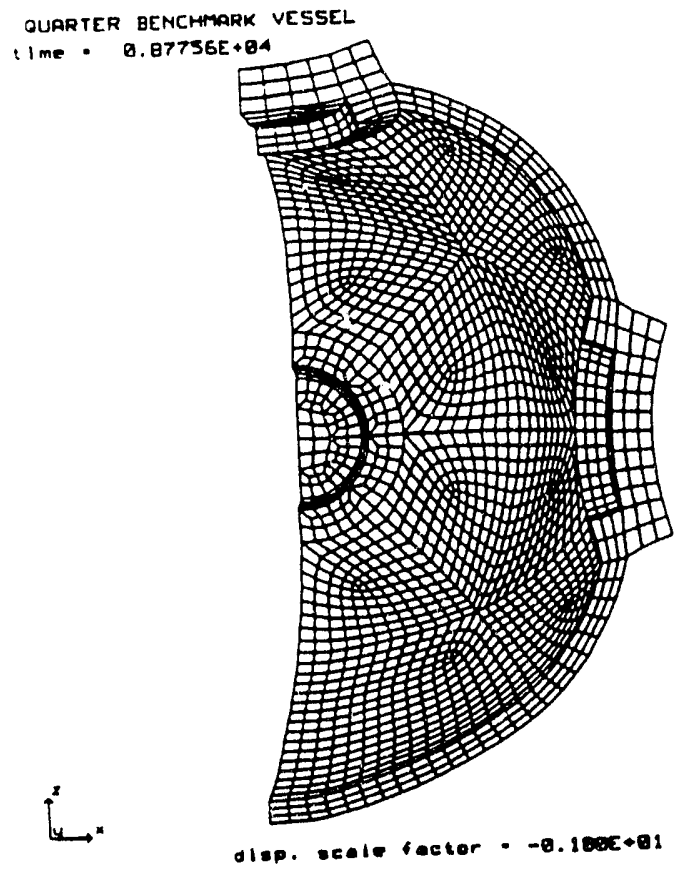

Figure 12: Predicted primary response mode shape.

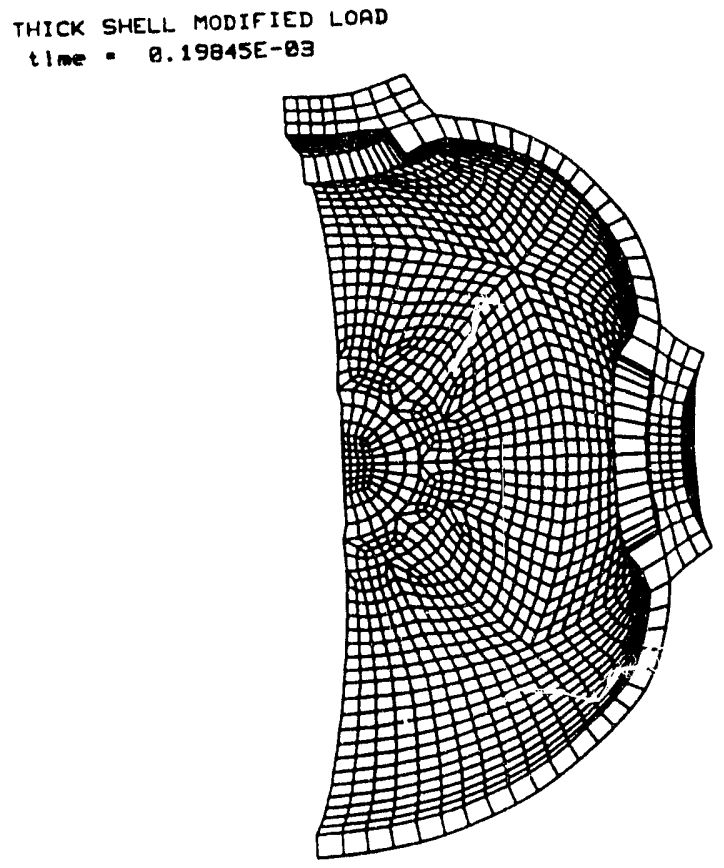

disp. scale foctor $0.200 E+83$

Figure 13: Predicted shape of vessel at first peak expansion. 
The frequency shown in Figure 14 is one of many bending modes predicted for the vessel. It is not exactly the same shape seen from the dynamic response analysis (Figure 9), but is similar to the response seen in the tests and to a lesser extent in the DYNA3D analysis. The response near the bottom (at approximately - 55 degrees latitude) is different at the 45 degree longitude than at 0 or 90 degrees longitude. Also, there is additional stretching of the center bottom. The mode shape show $n$ in Figure 14 has a natural frequency at about $1100 \mathrm{~Hz}$, agreeing well with the results of a Fourier transform of one strain channel as shown in Figure 15. This frequency is close enough to the primary response to cause the beating effect seen in the tests. We also noted that it has a period close to the time between reflections of the internal pressure pulse predicted by Al Bowman of LANL. We then decided to study the effect of the timing of the pressure reflections on the response.

We ran the thick-shell quarter-symmetric model using a load curve altered so that the period of the pressure reflections was closer to the period of the calculated bending mode shape. That is, we changed the timing of the pressure curve so the peak of each pulse occurred about 0.9 milliseconds apart. The resulting strains at the bottom are shown in Figure 16. There is a significant increase in the strain at the bottom of the vessel. Although the beating phenomenon is not visible, these results show that by changing the timing of the pressure reflections by approximately 15 percent, we have increased the strain by over 40 percent. Of the effects that we have studied, the timing of the pressure reflections is certainly the most influential. 


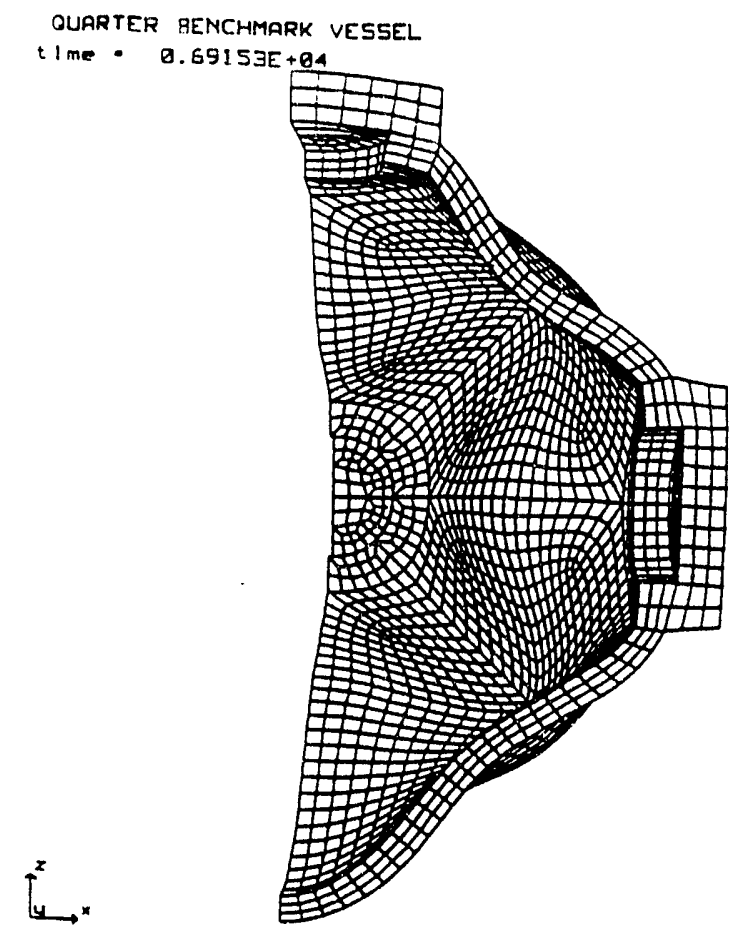

Figure 14: Bending mode shape of quarter-symmetric vessel.

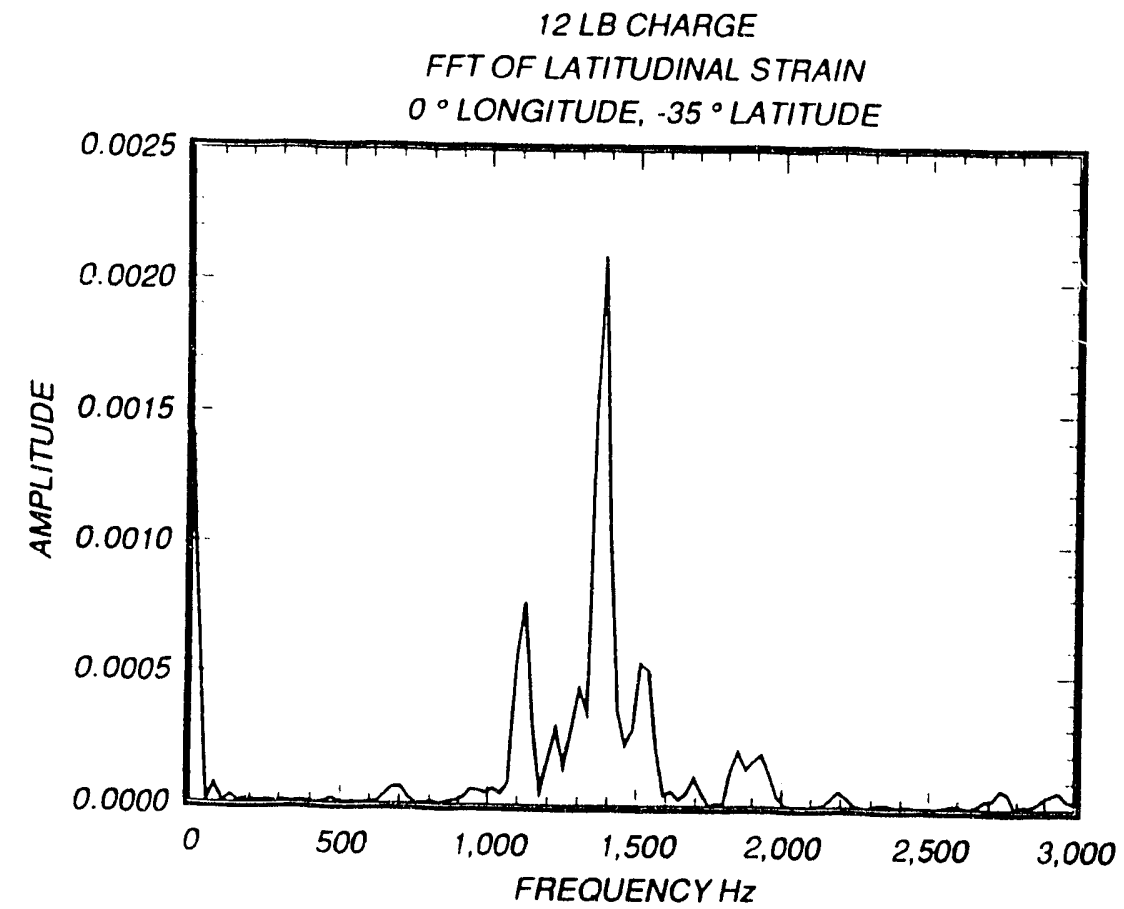

Figure 15: Fourier transform of strain gage reading from 12-lb test. 


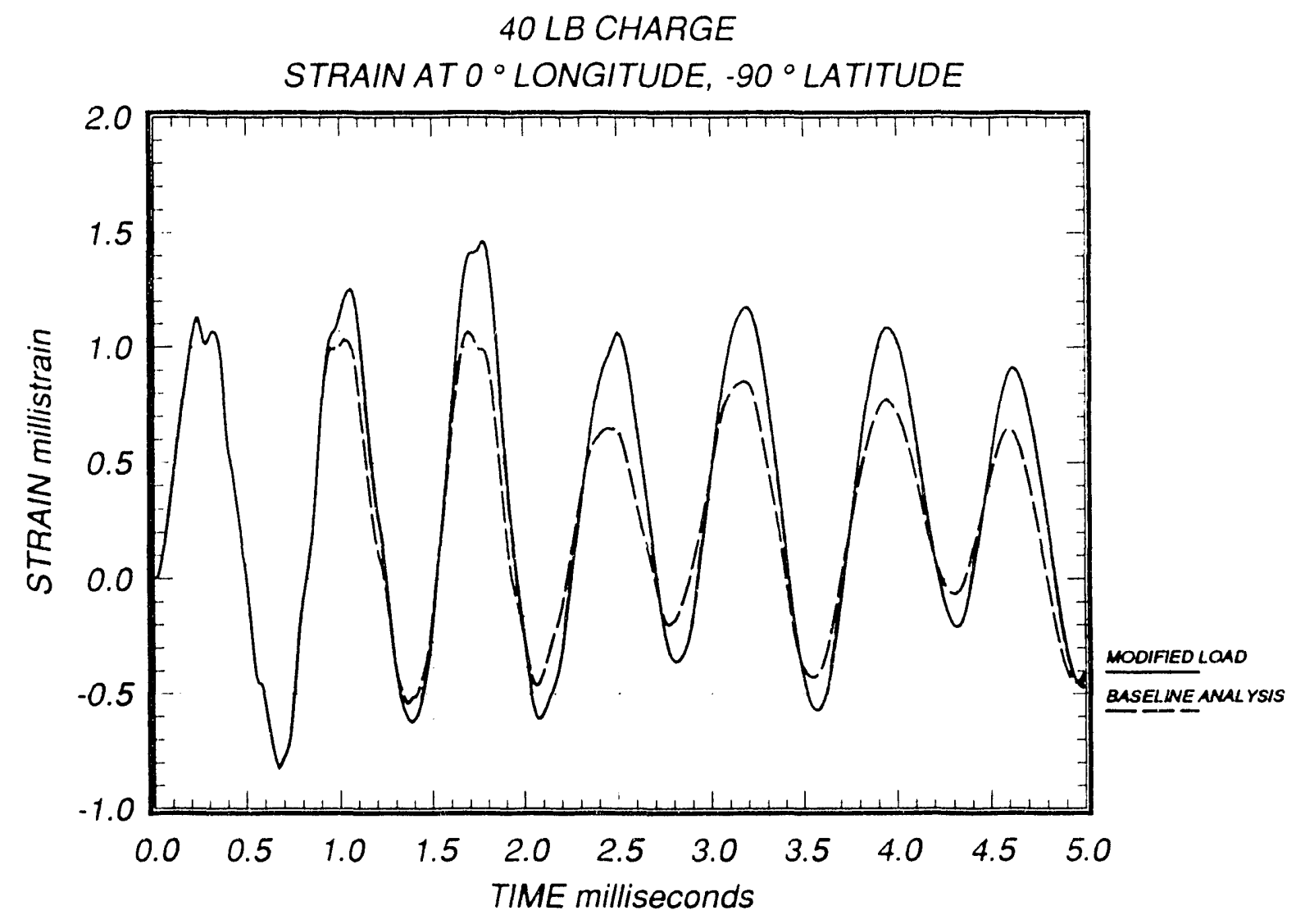

Figure 16: Predicted strains at the vessel bottom showing the effect of reflected pressure timing. 


\section{Conclusions and Recommendations}

The high strains seen at the bottom of the tested vessel are caused by the excitation of a bending mode superposed on the primary response. We believe that this bending mode is present in the finite element model, even in the quarter-symmetric model. However, this mode is being driven in tests by some mechanism which is not accounted for in the analysis. From this study we have determined that the effects of port mass, weld material inclusion, and overall thickness variation are not significant with respect to the response seen at the vessel bottom. A boundary condition applied to simulate the test sling did have a small effect, but not in the manner of the measured response. The most significant effect was due to changing the timing of the reflected pressure pulses. That effect was quite significant and nonlinear; for a 15 percent change in pulse timing, we got a 40 percent increase in strain.

The pressure pulse is the largest unknown present in the system. Measurements of pressure taken on previous tests failed to give good data, so all analyses have depended on an analytically predicted pressure curve. Also, the presence of instrumentation or mitigation materials should greatly reduce the reflected pressure and the bending response may decrease significantly. In view of the significance that the pressure pulse has on the predicted vessel response, we strongly recommend that Los Alamos take the steps necessary to measure the pressure history in future tests. 


\section{References}

(1) Brown, B. E. and Hallquist, John O., "An Inreractive Post-Processor for the Analysis Codes NIKE3D, DYNA3D, TACO3D, and GEMINI", UCID-19392, Lawrence Livermore Laboratory, Livermore, CA, July 1982.

[2] Hallquist, John O. and R. G. Whirley, "DYNA3D User's Manual (Nonlinear Jynamic Analysis of Structures in Three Dimensions)", UCID-19592, Lawrence Livermore Laboratory, Livermore, CA, Rev.5, May 1989.

[3] Lewis, Barbara B., "Confinement Vessel Analysis Final Report", APTEK, Inc., Colorado Springs, CO, May 6, 1992.

[4] Maker, Bradley N, Robert M. Ferencz, and John O. Hallquist, "NIKE3D A Nonlinear, Implicit, Three-Dimensional Finite Element Code for Solid and Structural Mechanics User's Manual ", UCRL-MA-105268, Lawrence Livermore Laboratory, Livermore, CA, January, 1991.

(5) PATRAN Plus User Manual Release 2.4, Publication Number 2191023, PDA Engineering, September 1989. 

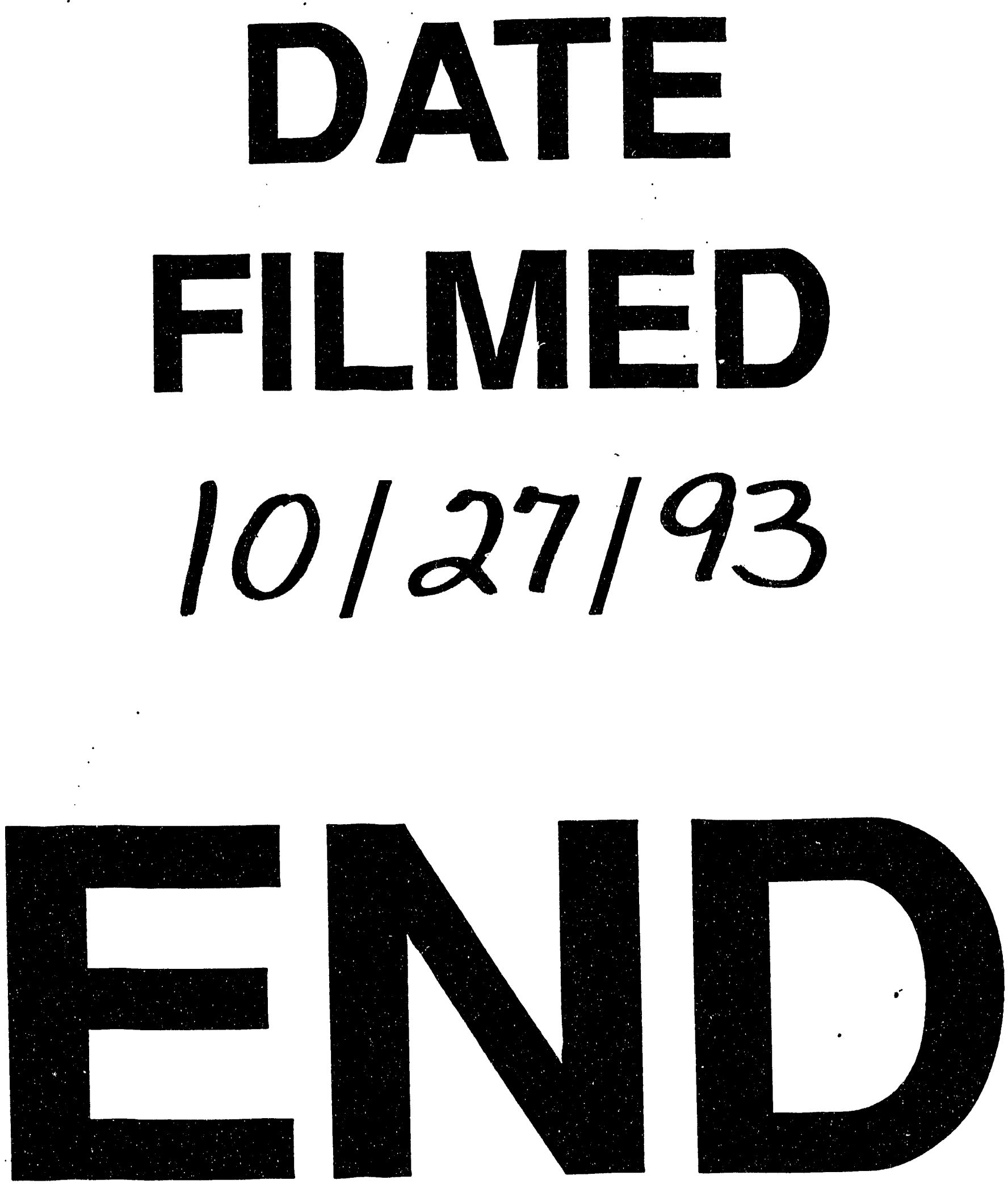
